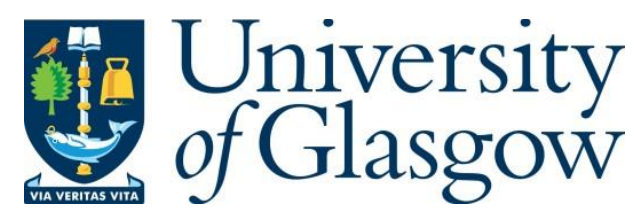

Holdsworth, C., Laverty, L. and Robinson, J. (2017) Gender differences in teenage alcohol consumption and spatial practices. Children's Geographies, 15(6), pp. 741-753.

There may be differences between this version and the published version. You are advised to consult the publisher's version if you wish to cite from it.

http://eprints.gla.ac.uk/175193/

Deposited on: 13 December 2018

Enlighten - Research publications by members of the University of Glasgow

http://eprints.gla.ac.uk 


\title{
Gender differences in teenage alcohol consumption and spatial practices
}

Accepted for Publication in Children's Geographies

This is the post-print version

Authors:

Clare Holdsworth

School of Geography, Geology and Environment, Keele University

c.m.holdsworth@keele.ac.uk

Louise Laverty Department of Sociology, Social Policy and Criminology, University of Liverpool 1.laverty@liverpool.ac.uk

Jude Robinson Department of Sociology, Social Policy and Criminology, University of Liverpool j.e.robinson@Liverpool.ac.uk

\begin{abstract}
In recent years teenagers have reported a decline in under-age drinking at the same time as their access to public space has been increasingly curtailed. In this paper we explore the spatial practices and drinking behaviours of a group of teenage girls and boys aged 13-14 years in Liverpool, UK. Our analysis considers how their use of space was bound up with experimentation with alcohol and how this varied by gender. We find in support of previous research that both girls and boys report nuanced experiences of public space, with some enjoying greater freedom while others have moved into more domestic and supervised leisure spaces in response to fears about their safety in public spaces. The boys also reported less alcohol consumption than the girls. These gendered experiences were mediated by social relationships and encounters with other young people, their parents and carers and other adults in positions of authority.
\end{abstract}

\section{Keywords}

Alcohol consumption, Teenagers, Public Space, Gender, leisure 


\section{Introduction}

Current guidance in the UK on under-age (less than 18 years of age) drinking focuses on the role of parents in supervising older children and instilling a sense of responsibility about drinking (Donaldson, 2009). Yet under-age drinking is also a practice through which teenagers may subvert parental control and create their own moral identities (Johnson 2013). These practices of subversion are inherently spatial; older children less than 18 years of age may choose to drink away from culturally-endorsed adult drinking spaces such as the home or restaurants. This is despite the fact that in the UK the home and other private spaces are places where young people (aged over 5 years) can legally drink. Outside home settings and unaccompanied by an adult in licensed restaurants, it is illegal for under-18s to buy or consume alcohol, and for adults to buy alcohol for them. The police have the power to confiscate alcohol from under-18s if they are drinking in a public place, and can prosecute adults for procuring alcohol for minors. Thus the regulation of teenage drinking is concerned with how teenagers acquire alcohol and where they consume it.

Research into the intersections between drinking and spatial practices for teenagers suggest that these are bound up with teenagers' experimentation with alcohol, particularly how much and what they drink; their ongoing relationships with parents and others in authority as they approach the transition to adulthood; and their need for authentic experiences that are not guided by parents (Johnson 2011). In recent years these liminal drinking practices have been targeted as anti-social behaviour and subject to increasing control which has seen teenagers' access to public space curtailed. The regulation of teenagers' independent mobility and their appropriation of public space has been an important theme in children's geographies in recent 
years, which has documented how public spaces are being foreclosed for children and young people (Benwell 2013; Jones 2000; Tucker and Matthews 2001). In this paper, we compare the experiences of girls and boys to examine if the push towards more regulation of teenagers in public space is also gendered. We consider if more recent experiences of teenage girls and boys in public space differ from earlier accounts. In particular, if the perceived greater vulnerability of girls is maintained, against concerns that teenage boys need support through troubled transitions, and how these anxieties relate to teenage alcohol consumption.

\section{Teenagers, gendered identities and public space}

The spatial context of younger people's lives is an essential component for differentiating children's agency against adult restrictions and is a key theme in children's and young people's geographies (see for example Evans 2008; Hall, Coffey and Williamson 1999; Holloway and Valentine 2000). While it is too simplistic to understand transitions to adulthood as a linear process in which young people become more autonomous as adult control and regulation are muted, in modern industrialised societies the culturally-embedded expectation is that social development entails autonomy. Yet the ambivalence of childhood and youth is that their emerging subjectivities are subject to constant surveillance and restriction (Valentine 1996a). While this ongoing tension between freedom and control is by no means a recent phenomenon, there is a tendency in both popular discourse and empirical research to present it as a topical and defining condition of childhood and youth and one that is constantly under threat (Benwell 2013; Karsten 2005). There is no fixed sense of a place for children and young people but generally the expectation is that both policy and everyday inter-generational encounters are closing down their access to public spaces (see for example Breitbart 1998; Collins and Kearns 2001; Driskell, Fox and Kudva 2008). 
The challenge for children's geographers is to provide an account of children's spatial practices that is more than descriptive. While it is not appropriate to generalise about spaces for children and young people as these are always in construction and contextual, it is also necessary to do more than provide detailed descriptions of children's geographies in order to capture the significance of these spatial practices. As Cope (2008) describes children are 'very good geographers' who can explain the physical and social fabric of where they live and make moral distinctions about these places. This experiential knowledge affords young people with 'street literacy', that facilitates their negotiation of localities (Cahill, 2000). Yet as Cahill's empirical observations illustrate, children's experiential learning is bounded by rules and regulated by others. The knowledge that children and young people learn about boundaries, difference and navigation develops a progressive sense of place that facilitates their self-awareness of being in place (Christensen and O'Brien 2003). For older children, privacy away from adults' supervision affords teenagers opportunities to experiment with different forms of expression and identity and this need for distance and separation requires them to be able to claim and appropriate space. As Abbott-Chapman and Robertson (2009: 420) suggest older children need to develop and rehearse 'in private within a restricted circle of close associates until perfected, in order for the actor to avoid embarrassment and disorientation and censure on the part of the wider "audience". The ambiguous quality of public spaces for teenagers is that these are often the only spaces where they can appropriate privacy (Childress 2004; Matthews, Limb and Taylor 1999; Robinson 2009). Matthews, Limb and Taylor's (2000) influential study of the street equates teenagers' appropriation of the street as a 'third space', neither public nor private, but rather a space where they can simultaneously celebrate a feeling of belonging and affirm a sense of difference. Their analysis effectively foregrounds the practices through which spaces are won out, and the 
wider significance of these practices and interactions rather than simply describing where and what these spaces are.

One way in which teenagers' use of space establishes social differences is in relation to gender and there are important differences between teenage girls' and boys' spatial practices. Previous research on teenagers' use of space has found that boys are more likely to report regular use of public space, specifically the street, than girls (Matthews, Limb and Taylor 2000). This does not necessarily infer that the street is a masculine space, as this would suggest an essentialist reading of children's spatial practices. Girls were active participants in street practices, though they were subject to greater regulation of their time outside of home than boys and the assumption that public space is masculine renders girls as invisible participants. Thus gendered spatial practices were relevant in framing the visibility of boys and girls on the street, rather than a dichotomous relationship between gender and public/private spaces (McDowell 1983).

Yet the assumption of girls' invisibility and the demarcation of masculine public space have been challenged and commentators (see for example Valentine, Skelton and Chambers 1998) suggest that from the late-1990s onwards greater recognition of feminine culture and agency has diminished gender differences. Thus the supposition that the street is primarily a place for boys is no longer valid. Yet though teenage girls may be more visible in public spaces, this does not necessarily imply gender-neutral experiences, particularly with reference to regulation of girls' and boys' behaviours. Changes in gendered practices also come about through shifts in boys' behaviour who are moving away from the street towards supervised and protected spaces through organised sports or in the home (McNamee 1998; Sweeting and West 2003). 


\section{Spatial practices of under-age drinking}

The regulation of alcohol consumption is inherently spatial. Legislative controls on consumption are bounded by both place and time as misdemeanours associated with alcohol relate to where it is purchased and consumed (Nicholls 2009). The political economy of drinking prioritises legally-sanctioned drinking spaces; a vibrant night-time economy is increasingly exclusive, concentrating on who is being served, rather than how liminal groups are increasingly excluded (Hannigan 1998). Research on urban drinking spaces has focused mainly on nightlife areas and has characterised these as contested spaces caught between contradictions of regulation and deregulation (Demant and Landolt 2014). As cities have become more entrepreneurial, nightlife spaces promote a particular version of hedonism that targets young people aged over 18. Yet this specific focus has created age-restricted social practices, which are either socially or legally enforced and younger teenagers have been excluded from these night-time spaces (Wilkinson, 2015). Yet a political economy approach can reinforce a restricted interpretation of alcohol consumption. As Jayne, Holloway and Valentine (2006) suggest it is germane to develop a more nuanced account of how social relations and cultural practices are associated with particular drinking practices and places (see also Townshend, 2013). We suggest that this approach could be applied to the spatial practices of under-age drinking, that the relationship between young people's experimentation with identity performances and drinking practices is inherently spatial.

Though it is not possible to attribute direct causality, spatial restrictions on teenagers have been concomitant with a continued decline in under-age experimentation with alcohol. In 2012, survey data on alcohol consumption found that $10 \%$ of school pupils in England had drunk alcohol in the last week, which continued a decline from 25\% in 2003 (Fuller 2013). 
This decline has been associated with the domestication of under-age drinking (Fuller 2013); reflecting changes in adult alcohol purchase and consumption (Holloway, Jayne and Valentine, 2008) and changing intergenerational relations and intimacy within families (Valentine, Jayne and Gould 2012). Survey data on drinking behaviours has found similar numbers of boys and girls reporting experimentation with alcohol; though this does not infer that teenage drinking is gender neutral. Differences remain in relation to type of drink (Fuller 2013) and drinking to intoxication, with teenage girls more likely to report having being drunk than boys (Farmer and Hanratty 2012). Yet the significance of gender does not just relate to how much boys and girls consume. Interconnections between spatial practices and drinking behaviours intersect with young people's social position and identities and in particular provide a venue for young people to experiment with masculine and feminine identities (Leyshon 2008; Simonen 2011). The similarity in teenage girls' and boys' alcohol consumption masks important differentials in where they drink, who they drink with and the consequences of drinking.

In this paper we consider the intersection of gender, space and drinking cultures for a group of teenage children aged 13-14 growing up in Liverpool, a city in North West England. We explore adolescents' negotiated spatial tactics and how these facilitate or reduce opportunities for alcohol consumption, comparing the experiences of teenage girls and boys. Through assembling the different players and localities that are involved in teenage boys' and girls' drinking behaviours the analysis develops a relational account of adolescent drinking, that also acknowledges the specificity of urban places.

\section{Methodology}


The research with teenagers was carried out through a series of focus groups conducted in secondary schools in Liverpool. Focus groups were used to allow participants to draw on their personal experience and knowledge of their immediate social groups (Backett-Milburn, Cunningham-Burley and Davis 2003). The focus groups facilitated social interaction and debate amongst peer groups about drinking practices (Demant and Jarvinen 2006). The decision to use focus groups was made in consultation with the funders and Liverpool Healthy School Team. As the main focus of the research was to explore young people's socialisation to alcohol the importance of peer relations was central to the project and focus groups were used to capture this dimension. However there are drawbacks in using this approach (Robinson 2012). In particular, careful attention needs to be given to safeguarding participants' privacy and ensuring that participants understood the implications of taking part, namely the impossibility of ensuring complete confidentiality for focus group participants even within groups of friends or classmates. Participants were advised not to 'over disclose', so say something that if it were repeated outside of the room would cause them distress or embarrassment. The research was approved by University of Liverpool's research ethics committee and all names and personal details were anonymised prior to analysis.

Six schools were recruited to take part in the research and were selected in collaboration with the Liverpool Healthy School Team. They comprised of one girls' school, two boys' schools and three mixed-sex schools. Single-sex focus groups were conducted due to the composition of local schools, and on the advice of the Youth Advisory Group based in a local community centre. As focus group researchers note, young people may have difficulties opening up when discussing topics that 'may have implications for gender identity' in mixed groups (Strange et al 2003, p209). The six schools selected were in three neighbourhoods of Liverpool chosen for their comparable demographic and socio-economic composition. Each neighbourhood 
has wards recognised as high on the index of multiple deprivations, in addition to often neighbouring wards of affluence. Pupils at the schools reflect this mixed demographic, whom the teachers identified as coming from both working class and middle class backgrounds. The majority of the pupils were from a white ethnic background reflecting the composition of the area more widely.

The focus groups took place in the schools between October 2010 and May 2011. In each school, all pupils in year 9 (age 13-14) were given information sheets and consent forms as well as information sheets to give to their parents/carers with the option to opt their child out of the study. Young people were invited to take part in single sex focus groups in each school. In total 58 pupils consented to take part in the study ( 31 males and 27 females) and nine focus groups were completed with approximately five to nine pupils in each group lasting the duration of a school lesson (50 minutes) on average. Teachers selected friendship groups from those who consented to take part. Some teachers admitted picking a group they thought would 'behave' whilst others picked groups they thought had more 'experience' on the topic. Whilst each scenario is problematic, the result was a variety of actual, and anticipated, experiences across the study. The topic guide was developed based on existing literature on young people and alcohol consumption and in consultation with the Youth Advisory Group. This topic guide covered: young people's lives in and out of school, perceptions of alcohol and other health related behaviour, parental strategies around alcohol, school strategies around alcohol, and prevention messages. Visual prompts (media clippings) were also used to initiate discussion. 
The focus groups were recorded and this was explained to all participants prior to taking part and their consent was obtained for this. Given the shared and semi-public nature of the research process, the facilitator was aware that participants were performing for both herself, the recording and their peers (Zeller 1993). Furthermore, the focus groups were facilitated by one of the authors (LL) who was in her 20s, white, female, with experience of underage drinking. However, youth researchers have warned that adult researchers can colonise young people's experiences through claiming insider status by having been a young person. In addition, in school settings adults and young people are often in hierarchical relationships. As such, the facilitator was cautious to act in a non-hierarchical manner, allowing young people to direct the research, whilst not claiming an insider status in regards to age or experience.

Participants' willingness to describe particular escapes or present themselves in a certain light was to some extent influenced by the research process; as such the narratives do reflect an idealised version of the young people's drinking experiences (Madriz 1998). Our intention is not to present the data as verifiable accounts of young people's drinking, but rather as an exploration into the practices that are expressed by young people and that other young people are likely to identify with. The analysis used a thematic approach, with all of the authors coding independently using NVivo, and then comparing analysis to develop a coding framework and refine final themes (Silverman 2013). We discuss the main findings relating to participants' discussion of spatial and drinking practices and how these differ between the focus groups for girls and boys.

\section{Analysis}

\section{Spatial practices}

Across the nine focus groups teenage boys and girls reported different spatial practices. When asked what they did in the evenings, in all of the boys' focus groups, participants 
discussed taking part in activities such as football. Playing football was almost exclusively associated with being a member of a team and playing in organised matches, not playing with friends in the street or park. Not all boys played football, others described more domesticated free time associate with playing computer games at home, 'Joel just stays with his PlayStation', while a few mentioned going fishing or going into town. This supports more recent research with teenage boys that suggests there has been a move away from unsupervised but visible street and parks towards supervised spaces (Bromley and Stacey 2012; Lincoln 2012). The boys identified themselves through their activities and they distinguished their friends with reference to specific activities: 'Alex plays football' 'Kieran he goes swimming' [Boys FG School 4].

In contrast the girls in the focus groups did not report participation in organised activities, there was no equivalent or football for the girls reflecting that there are fewer organised activities that are provided for girls or that girls want to go to (Skelton 2000; Tucker and Matthews 2001). The girls in the focus groups confirmed their exclusion from youth and leisure services; highlighting that not only are there less leisure services for girls, but that existing youth service spaces remain controlled and dominated by boys (Griffiths 1988; Nava 1984; Thorne 1993; Tucker and Matthews 2001). In one focus group, the girls discussed their liminal experiences:

Rachel: When you think about it, when people say do you go out and that, we are quite boring because all we do is walk around. So it is quite boring.

Lisa: You have a laugh though.

Rachel: Like we are supposed to do, we are at that age where we just, we just, we are too young to, we are too old for playing and we are too young to do anything else.

Girls FG School 3 
Yet the difference in spatial practices for the boys and girls did not just relate to the kinds of activities that they took part in but their willingness to spend time outside of the home. For example, some of the boys discussed their fear of being out alone, especially after dark:

Gareth: And I don't go out in the dark only of a weekend when I finished my football, well finish about 12 o'clock, get ready and go out and come home about 6 or 7 . Because when it's that dark you don't know what, if you go to the park you don't know what is there, do you?

\section{Boys FG School 3}

For these boys this fear was not imagined. In 2007 an 11-year old boy, Rhys Jones, was shot in the back by a 16 year-old as he walked home from football practice in a suburb of Liverpool. This incident happened four years prior to the research but was a significant event for the boys. His murder was explicitly mentioned in one of the focus group, though was not mentioned by any of the girls. The boys commented that Rhys was not the intended victim; he was in the wrong place at the wrong time - walking home from football practice - as the boys themselves did. For the boys returning from football practice was risky:

Leon: Even in the park, I get, I always think when I am walking home on my own, I think Rhys Jones was just doing this, walking home on his own and a lad shot, tried to shoot someone else but he got in the way. So when I am walking home, sometimes I jog home or sometimes like looking around to see if anyone is there.

Boys FG School 3

The boys demonstrated a keen sense of danger and how to avoid being singled out and their tacit knowledge of local geographies was an important resource (Jupp 2007). They were 
knowledgeable about the importance of moving quickly, or being with others, and of the significance of dressing appropriately to avoid identification with certain groups. Dangers could therefore be avoided through adopting appropriate tactics of resistance. These tactics were, as De Certeau (1984) defines, conditioned by an absence of power in response to diverse authorities of formal and informal power relations. The boys' tactics were not just developed against authority figures, such as the police who would move groups of three or more boys on, but involved other teenagers as well. While tactics were framed against incidences such as Rhys Jones' murder, they were also developed in response to more everyday fears and interactions with other young people (Percy-Smith and Matthews 2001).

The girls expressed fear of being out after dark, yet they identified security with being on home ground (Pain 2003). Some girls claimed that they were safe in their local neighbourhoods, though would be wary if they were further from home. They associated fear in public spaces, particularly local parks, with stranger danger and risk of being stabbed, kidnapped or jumped upon by strange men. Unlike the boys they did not talk about being fearful of other teenagers. Yet, similar to earlier research on the regulation of girls in public spaces (Matthews, Limb and Taylor 2000) they reported that their freedom outside of the home was monitored by parents and they were expected to observe pre-arranged times about getting home, or keep their parents informed about where they were:

Stacey: But if I was to like text her and tell her the reason I was late home then I don't think she would mind if it was something like traffic, but if I was like late home with no reason then she most probably would ground me.

Girls FG School 2 
While some boys also mentioned curfews, this was not theme for discussion in the focus groups, except for brief comparisons of who had a curfew and who did not. The role of parental control was not discussed by the boys as they described their desire to get home quickly from activities such as football. They were more concerned about avoiding confrontations with other young people. Yet the limited curfews for boys could also reflect the continuation of gendered practices that render girls behaviour to more immediate scrutiny within the family (Tucker 2003), while the regulation of boys' behaviour is negotiated on the street.

\section{Drinking Spaces}

In this qualitative dataset both boys and the girls agreed that at their age, in Liverpool, more girls drank than boys. This reflects previous, quantitative, research with teenagers that reports girls at this age (13/14) are more likely to have had a drink than boys, though this difference diminishes among older teenagers (Bremner et al. 2011). In the focus groups the girls were more knowledgeable about the kinds of drinks that teenagers consumed and admitted to drinking 'Vodka, wine, lambrini'. In one focus group the girls suggested that it was unusual to see boys drinking:

Lisa: Like when you see a lad drinking, don't know it's just like different because you see girls drinking all the time don't you? It's unusual. Even at school like you see girls drinking.

Girls FG School 3

One explanation of this difference was that boys were more likely to smoke cannabis, while girls preferred alcohol. Another characteristic that the girls and boys agreed with was that peer pressure was a reason that some teenagers drank (Johnson 2013), though they 
themselves did not admit to this. For example, one group of boys described a party where other boys their age were encouraged to get drunk and smoke cannabis by older boys, though did not associate themselves with this behaviour:

Gary: All the older lads were drunk and were giving all the younger lads who wanted to be hard, alcohol, weed. A couple of lads our age smoked weed because they wanted to be hard, and like got drunk, and a couple of them got grounded for ages because they wanted to look hard in front of a couple of 18 year olds.

\section{Boys FG School 2}

Moreover, the boys concurred with the exclusion of teenagers from night-time economy and the increasing use of security (guards and ID) to police this. One reason that they gave for not drinking is that it would put them in greater risk of being attacked by other teenagers: Ryan: If you are drunk, like the first time if you got proper drunk and you are out in town you wouldn't know your way home and you would probably walk into danger or something because gangs everywhere.

Craig: Yes, when you are drunk you don't know what you are doing do you? You might be singing Liverpool or Everton [Football clubs] songs.

\section{Boys FG School 1}

Being drunk was associated with lack of control but rather than embracing this, the boys were more concerned about the need to act maturely and correctly, for example not singing inappropriate football songs. The boys sought to distance themselves from other teenagers who drank in public and expressed disapproval about this drinking behaviour (Townshend and Roberts, 2013). They described seeing boys their own age 'with a crate of Smirnoff Ice' [alcohol pop] and while they dismissed this activity as stupid they were also wary about what 
these boys could do to them. This generalising of other teenagers was used to demarcate the boys' own behaviour (they did not sit around in parks drinking but were aware that other boys their age did) but also to identify that they themselves were in danger. The boys' avoidance of drinking was also associated with their participation in organised sports and, for some, ambitions to become a footballer: 'Alex can't drink anyway because like he is a good footballer and he would end up getting dropped from the team' [Boys FG School 4]. In this way the boys traded competency in football against drinking and defined themselves through these non-drinking leisure activities (De Visser and Smith 2007).

The girls also described how other young people hung out in parks:

Shannon: Like when you are out like say like in a big field or something like [Name] Park, they find lots of teenagers drinking because maybe in quiet places where they are not going to cause no harm.

\section{Girls FG School 1}

In contrast to the boys they did not see this behaviour as threatening (though they did not admit to taking part in this activity themselves) and were more ready to admit that they knew these 'other' teenagers. They were also knowledgeable about how to obtain alcohol:

Kara: Yes it's because older people like, like the eldest in the kind of group thing you know sometimes go into the shops and ask for stuff.

\section{Girls FG School 1}

When asked who they would ask to buy alcohol for them the girls stated that it was 'smackheads' a derogatory term used for someone on the streets who was dependent on either drugs or alcohol. Yet the girls' attempt to acquire alcohol was often thwarted by the police 
who would approach people buying alcohol for teenagers and patrolled the parks where young people drank:

Kirsty: Like there is police in [name] Park you know in them like vans, they like they go round and like look in your bags and actually take your drinks off you.

Jodie: And pour them down the drain and make you pour them down the drain.

\section{Girls FG School 3}

Yet while the girls were aware that other young people went out drinking they also claimed that it was only a minority that did so, and that this minority gave other teenagers a bad name and was reported in local and national media. They were aware that the neighbourhoods where they lived were not the 'best' places and they witnessed problems with excessive drinking at all ages.

In one of the girls' focus groups participants were willing to talk about their drinking escapades, including ending up in hospital. They admitted that their drinking led to them being out of control, precisely the kind of behaviour that the boys were frightened of:

Samia: Yes, we went out and we got lost, all the lads got like becks [bottled beer] and all them because like there was some place where we used to go on the field. I was running around I didn't know what I was doing, shouting, 'Izzy I love you!' and everything, I didn't know what I was saying. Shouting, 'Izzy, Izzy I love you!'.

\section{Girls FG School 4}

The girls' discussion of drinking episodes reinforced the social context of under-age drinking. As well as encouraging others to drink, presence of friends was also important for regulating drinking behaviours and ensuring that they did not get into the kinds of trouble that the boys 
sought to avoid. However, their drinking confessions were discussed as past experiences and ones that they, and other girls, had grown out of:

Abi: When we were in Year 7 you seen more people like out drinking then, but now, you see people out but you don't see them drinking in the parks

\section{Girls FG School 4}

Hence both the boys and girls were careful about admitting to under-age drinking in the context of the focus groups, but the girls were more knowledgeable and less fearful of the consequences of drinking, particularly for their own safety. When they did talk about their own drinking, the girls sought to qualify this by claiming that they were now more mature and sensible. The reasons for this reported change in drinking practices were not discussed, other than that they were keen to present themselves in the focus group as more mature and that they had learnt from their earlier experiences. They also compared their behaviour with girls from other neighbourhoods in Liverpool, suggesting that they were not as out of control as other teenage girls in the city. Hence these drinking narratives were carefully balanced between endorsing the drinking practices that demarcated them as teenagers but at the same time, evoking a moral code that regulated their behaviour (Johnson 2011).

The girls also talked about how parents' regulated their drinking. The girls recounted that mothers in particular were concerned about their safety and preferred that they drank at home rather than outside. Parental response to teenage drinking was to ensure their children's safety rather than prohibition. As long as the girls did not exceed the limits of appropriate behaviour, related to where and how much they drank, they were allowed to experiment: 
Carina: My mom said to me she doesn't want me drinking on the streets. I remember we were on holiday she let me drink next to her, so I think it's like under her supervision but when I have been drunk she has grounded me.

\title{
Girls FG School 4
}

\begin{abstract}
Although the girls described more mobility freedom than the boys and, as a consequence, drinking more, they also had to negotiate instructions from parents about respectability and the risks of public spaces.
\end{abstract}

\section{Discussion}

Both the girls' and boys' account of spatial behaviours concurs with Valentine, Skelton and Chambers's (1998) assertion that greater recognition of feminine culture and agency has brought about a change in teenagers' spatial practices, but not that gender differences are diminished. There were differences in how the teenagers described their leisure activities, but these were not demarcated by a dichotomous division between domestic and public that mapped onto girls' and boys' behaviours. The difference in the boys' and girls' accounts was not a matter of visibility, but of forms of behaviour. The boys' accounts were distinguished by engagement in organised activities, going to football practice rather than hanging out with friends, and were also more home-based through playing computer games. The boys had benefitted from the expansion of organised leisure activities (Roberts 2012) which targets boys rather than girls. For the girls there was no equivalent of organised activities such as football, and the absence of formal activities is likely to be structured by class and locality as well as gender (Skelton 2000). The absence of girls from these activities is an important characteristic of youth work, which continues to be framed by masculine identities and behaviours (Wimbush and Talbot 1988). However, while the boys who took part in the focus 
group described leading quite domesticated and regulated lives, this was articulated against boys (and girls) who did not. The boys acknowledged how their movements outside of the home were monitored by both adults in position of authority (particularly the police) but were more concerned with their encounters, or potential encounters, with other young people. The boys were wary of older teenagers and those who drank in public spaces. It is important to note that this may also reflect age differences, as Bromley and Stacey (2012) suggest that younger boys are more likely to report their anxieties whilst older boys downplay them.

In contrast the girls were trapped between freedoms associated with younger childhood and adult behaviours that they could not yet buy into. These more liminal practices were subject to greater surveillance by adults, both parents and police (Tucker 2003). In contrast to the boys their geographical knowledge distinguished local neighbourhoods and other places. What mattered for the girls was where they were in the city, in their local neighbourhoods they could hang out with their friends in relative safety. Thus the girls were more territorial than the boys and more willing to distinguish between localities they felt safe or intimidated in, but also talked more about boredom and frustration.

These differences in spatial practices were associated with reported drinking behaviours. While aware that other teenagers did hang out in public spaces to drink the boys were less likely to admit to knowing these 'other' boys and girls. The boys used this diversity of different behaviours to establish their own identities. For example, the boys were footballers, fishermen, or gamers; they were not, for the most part, drinkers. In contrast the girls were less concerned about other young people and were more willing to admit to being a teenage drinker in local parks. Moreover, as they were drinking more than the boys, their drinking was also subject to parental surveillance, who preferred that if they were going to drink that 
this was in the safety of the home, rather than the park. The girls did not trade competencies in drinking against other activities. In contrast with the boys, the girls' greater spatial autonomy was associated with less choice about lifestyles and identity, as the boys could choose an alternative path of sports-based competence over drinking (De Visser and Smith 2007).

One important question is the extent to which these behaviours are framed in a particular time and space. Liverpool is a UK city that has had a number of youth gang-related incidences, including the shooting of Rhys Jones, though this does not infer that there is a 'gang' problem in the city, most young people are not involved in these activities (Smithson et al. no date). Yet while these criminal and anti-social behaviours engage a very small number of older children and young people, they do impact on others. Strategies to target anti-social behaviour in Liverpool and other UK cites are having a marked effect on young people, though not those who are engaging in the practices that the authorities are seeking to restrict. Targeting the regulation of space rather than preventing behaviour has implications for a much wider group of young people and the demonization of young people's anti-social behaviour is articulated by the young people that are excluded by this very discourse. In Liverpool it would appear that some young people, in this case certain groups of teenage boys, are excluding themselves from public space. Yet this exclusion is brought about through their own interactions with other young people as well as adults in authority and is facilitated through access to organised leisure facilities.

\section{Conclusion}

The focus group discussions reveal how the ongoing processes of appropriation and dispersal in teenagers' spatial practices are not just regulated across generations (Benwell 2013). The 
teenagers who we spoke to, and particularly the boys, described how it is not just adults who were fearful and frightened by young people in urban contexts, young people were also wary of their peers (Bromley and Stacey 2012; Cops 2013). Teenagers'street literacy is developed not just through their own experiences but through encounters with peers and adults (Cahill, 2000). In this aspect the analysis contributes to literature on young people and public space but it also responds to calls for a relational approach to geographies of age in drawing attention to how this regulation and control is carried out by young people on each other (Hopkins and Pain 2007; Vanderbeck 2007). In addition to promoting curfews as mechanisms for removing juvenile criminals from the streets, these mechanisms of dispersal also protect 'innocent' children and young people from the violence of the public realm (Valentine 1996b). Yet our analysis suggests that these might be crude distinctions that are used to divide and essentially undermine the validity and visibility of young people's experiences, but they are also distinctions employed by young people and children themselves. Teenagers' territoriality is implicitly social and spatial practices are collective experiences, hence they regulate and disperse each other's spatial interactions.

For the teenagers in this study the regulation of spatial behaviours is associated with access to drink. The girls described how their access to alcohol was mediated through hanging out with other young people, rather than drinking at home, despite the fact that this was, for most girls, sanctioned by parents. The boys were not drinking either with friends or at home but were rather investing in identities as footballers or gamers. It could be that the boys are delaying these behaviours, as the gender gap in under-age drinking diminishes with age. Thus these mid-teenage identities as footballers or gamers could become drinkers in future years. In response to recent calls for a relational approach to children and young people's geographies, this study of adolescents in Liverpool highlights the varied actors that are 
involved in both facilitating and regulating teenage drinking behaviours. In particular, young people monitor each other's drinking and, as reported in the context of a focus group, this is often disapproving, though teenagers also support each other in experimenting with intoxication. This research also suggests that as opportunities to socialise in public space are increasingly restricted for teenagers, particularly for boys, this also limits opportunities for drinking which might provide an explanation for recent declines in adolescent alcohol consumption.

\section{Acknowledgements}

This research was funded by the Liverpool Health Inequalities Research Institute. We would like to thank the young people and schools for taking part in this research and for the two referees for their insightful comments on the paper. 


\section{References}

Abbott-Chapman, J. and M. Robertson. 2009. “Adolescents' Favourite Places: Redefining the Boundaries between Private and Public Space." Space and Culture 12(4): 419-434. doi:10.1177/1206331209348091.

Backett-Milburn, K., S. Cunningham-Burley and J, Davis. 2003. "Contrasting lives, contrasting views? understandings of health inequalities from children in differing social circumstances.” Social Science and Medicine 57(4): 613-623. doi:10.1016/S02779536(02)00413-6.

Benwell, M.C. 2013 "Rethinking conceptualisations of adult-imposed restriction and children's experiences of autonomy in outdoor space." Children's Geographies 11(1): 28-43. doi:10.1080/14733285.2013.743279.

Breitbart, M. 1998. “'Dana’s Mystical Tunnel': Young People’s Designs for Survival and Change in the City." In Cool Places: Geographies of Youth Cultures, edited by T Skelton and G Valentine, 305-327. London: Routledge.

Bremner, P., J.Burnett, F. Nunney, M. Ravat, and W. Mistral. 2011. Young People, Alcohol and Influences A Study of Young People and their Relationship with Alcohol. York: Joseph Rowntree Foundation.

Bromley, R.D.F. and R.J. Stacey. 2012. "Feeling unsafe in urban areas: exploring older children's geographies of fear." Environment and Planning A 44(2): 428-444. doi:10.1068/a44224.

Cahill, C. 2000. "Street literacy: urban teenagers' strategies for negotiating their neighbourhood. Journal of Youth Studies 3(3): 251-277. 
Childress, H. 2004. "Teenagers, territory and the appropriation of space." Childhood: A Global Journal of Child Research 11(2): 195-205. doi:10.1177/0907568204043056.

Christensen, P.M. and M. O'Brien. 2003. Children in ihe City: Home, Neighbourhood and Community. London: Routledge.

Collins, D.C.A. and R.A. Kearns. 2001. "Under curfew and under siege? Legal geographies of young people." Geoforum 32(3): 389-403. doi:10.1016/S0016-7185(00)00033-6.

Cope, M. 2008. "Patchwork neighborhood: children's urban geographies in Buffalo, New York.” Environment and Planning A 40(12): 2845-2863. doi:10.1068/a40135.

Cops, D. 2013. "The role of autonomous mobility in public space on fear of crime among adolescents.” Journal of Youth Studies 16(8): 1105-1122. doi:10.1080/13676261.2013.793790.

De Certeau, M. 1984. The Practice of Everyday Life trans. S Rendall. Berkeley: University of California Press.

De Visser. R.O. and J.A. Smith. 2007. “Alcohol consumption and masculine identity among young men.” Psychology \& Health 22(5): 595-614. doi:10.1080/14768320600941772.

Demant J. and M. Jarvinen. 2006. "Constructing maturity through alcohol experience - Focus group interviews with teenagers.” Addiction Research \& Theory 14(6): 589-602. doi:10.1080/16066350600691683.

Demant, J. and S. Landolt 2014. "Youth drinking in public places: the production of drinking spaces in and outside nightlife areas." Urban Studies 51(1): 170-184. doi:10.1177/0042098013484532. 
Donaldson, L. 2009. Guidance on the Consumption of Alcohol by Children and Young People London: Department of Health, Available at http://webarchive.nationalarchives.gov.uk/20130107105354/http:/www.dh.gov.uk/prod_cons um_dh/groups/dh_digitalassets/documents/digitalasset/dh_110256.pdf. Accessed December 2015.

Driskell, D., C. Fox and N. Kudva. 2008. "Growing up in the new New York: youth space, citizenship, and community change in a hyperglobal city." Environment and Planning A 40(12): 2831-2844. doi:10.1068/a40310.

Evans, B. 2008. “Geographies of youth/young people.” Geography Compass 2 (5): 16591680. doi:10.1111/j.1749-8198.2008.00147.x.

Farmer, S. and B. Hanratty. 2012. "The relationship between subjective wellbeing, low income and substance use among schoolchildren in the north west of England: a crosssectional study." Journal of Public Health 34(4): 512-522. doi:10.1093/pubmed/fds022.

Fuller, E. (ed) 2013. Smoking, Drinking and Drug Use Among Young People in England, 2012. London: Health and Social Care Information Centre, Lifestyles Statistics.

Griffiths, V. 1988. “From 'playing out' to 'dossing out': young women and leisure.” In. Relative Freedoms: Women and Leisure. Edited by E. Wimbush and M. Talbot, 48-59. Milton Keynes: Open University Press.

Hall, T., A, Coffey and H. Williamson. 1999. "Self, space and place: youth identities and citizenship.” British Journal of Sociology of Education 20(4): 501-513.

doi:10.1080/01425699995236 
Hannigan. J. 1998. Fantasy City: Pleasure and Profit in the Postmodern Metropolis. London: Routledge.

Holloway, S.L. and G. Valentine (eds) 2000. Children's Geographies: Playing, Living, Learning. London: Routledge.

Holloway, S.L., M. Jayne and G. Valentine. 2008. “'Sainsbury's is my local': English alcohol policy, domestic drinking practices and the meaning of home." Transactions of the Institute of British Geographers 33(4): 532-547. doi:10.1111/j.1475-5661.2008.00322.x.

Hopkins, P. and R. Pain. 2007. "Geographies of age: thinking relationally." Area 39 (3): 287294. doi:10.1111/j.1475-4762.2007.00750.x.

Jayne. M., S.L. Holloway and G. Valentine. 2006. "Drunk and disorderly: alcohol, urban life and public space." Progress in Human Geography 30(4): 451-468. doi:10.1191/0309132506ph618oa.

Johnson, P. 2011 “'You just get blocked; teenage drinkers: reckless rebellion or responsible reproduction?" Children \& Society 25(5): 394-405. doi:10.1111/j.1099-0860.2009.00288.x.

Johnson, P. 2013 “'You think you're a rebel on a big bottle': teenage drinking, peers and performance authenticity." Journal of Youth Studies 16(6): 747-758.

doi:10.1080/13676261.2012.744816.

Jones, O. 2000. "Melting Geography: Purity, disorder, childhood and space". In Children's Geographies: Playing, Living, Learning. Edited by S.L. Holloway and G. Valentine, 29-47. London: Routledge. 
Jupp, E. 2007. "Participation, local knowledge and empowerment: researching public space with young people.” Environment and Planning A 39(12): 2832-2844. doi:10.1068/a38204.

Karsten, L. 2005. "It all used to be better? Different generations on continuity and change in urban children's daily use of space. “Children's Geographies 3(3): 275-290. doi:10.1080/14733280500352912.

Leyshon, M. 2008. “'We're stuck in the corner': Young women, embodiment and drinking in the countryside." Drugs-Education Prevention and Policy 15(3): 267-289. doi:10.1080/09687630801920286.

Lincoln, S. 2012. Youth Culture and Private Space. Basingstoke: Palgrave MacMillan.

Madriz, E. 1998. "Using focus groups with lower socioeconomic status Latina women.” Qualitative Inquiry 4(1): 114-128. doi:10.1177/107780049800400107.

Matthews, H., M. Limb and M. Taylor. 1999. "Reclaiming the street: the discourse of curfew." Environment and Planning A 31(10): 1713-1730. doi:10.1068/a31171.

Matthews, H., M. Limb and M. Taylor. 2000. “The street as thirdspace.” In Children's Geographies: Playing, Living, Learning. Edited by S.L. Holloway and G. Valentine, 54-67. London: Routledge.

McDowell, L. 1983. "Towards an understanding of the gender division of urban space." Environment and Planning D: Society and Space 1(1): 59-72. doi:10.1068/d010059.

McNamee, S. 1998. "Youth, gender, and video games: power and control in the home." In Cool Places: Geographies of Youth Cultures. Edited by T. Skelton and G. Valentine, 195-206 London: Routledge 
Nava, M. 1984. "Youth service provision, social order and the question of girls". In Gender and Generation. Edited by A. McRobbie, and M. Nava, 1-30. Basingstoke: Palgrave MacMillan.

Nicholls, J. 2009. The Politics of Alcohol: A History of the drink question in England. Manchester: Manchester Univeristy Press.

Pain, R. 2003. "Youth, age and the representation of fear." Capital \& Class 27(2): 151-171. doi:10.1177/030981680308000109.

Percy-Smith, B. and H. Matthews. 2001. "Tyrannical spaces: young people, bullying and urban neighbourhoods." Local Environment 6(1): 49-63. doi:10.1080/13549830120024242.

Pickering, J., K. Kintrea and J. Bannister. 2012 "Invisible walls and visible youth: territoriality among young people in British cities.” Urban Studies 49(5): 945-960. doi:10.1177/0042098011411939.

Roberts, K. 2012. "The leisure of young people in contemporary society.” Arbor, 88(754): $227-337$

Robinson, C. 2009. “'Nightscapes and leisure spaces': an ethnographic study of young people's use of free space." Journal of Youth Studies 12(5): 501-514. doi:10.1080/13676260903081657.

Robinson, J. 2012. “Using focus groups”. In Handbook of Qualitative Research in Education. Edited by S. Delamont, 391-404. Cheltenham: Edward Elgar.

Simonen, J. 2011. "In control and out of control: The discourse on intoxication among young Finnish women in the 1980s and 2000s." Nordic Studies on Alcohol and Drugs, 28(2), 131147. doi:10.2478/v10199-011-0014-3. 
Silverman, D. 2013. Doing Qualitative Research: A Practical Handbook. $4^{\text {th }}$ Edition. London: Sage.

Skelton, T. 2000. “"Nothing to do, nowhere to go': teenage girls and public space in the Rhondda Valleys, South Wales.” In Children's Geographies: Playing, Living, Learning. Edited by S.L. Holloway and G. Valentine, 80-99. London: Routledge.

Smithson, H., K. Christmann, R. Armitage, L. Monchuk, A. Whitehead and M. Rogerson (no date) Young People's Involvement in Gangs and Guns in Liverpool. Huddersfield: Applied Criminology Centre.

Strange, V., Oakley, A., Forrest, S. and The Ripple Study Team. 2003. "Mixed-sex or singlesex sex education: how would young people like their sex education and why?" Gender and Education 15(2):201-214.

Sweeting, H. and P. West, P. 2003. "Young people's leisure and risk taking behaviours: changes in gender patterning in the West of Scotland during the 1990s." Journal of Youth Studies 6(4): 391-412. doi:10.1080/1367626032000162113.

Townshend, T.G. 2013. "Youth, alcohol and place-based leisure behaviours: a study of two locations in England." Social Science \& Medicine. 91: 153-161.

Townshend, T.G. and Roberts, M. 2013. "Affordances, young people, parks and alcohol consumption. Journal of Urban Design. 18(4):494-516.

Thorne, B. 1993. Gender Play: Girls and Boys in School. Buckingham: Open University Press. 
Tucker, F. 2003. “Sameness or Difference? Exploring Girls' Use of Recreational Spaces.” Children's Geographies 1(1): 111-124. doi:10.1080/14733280302187.

Tucker, F. and H. Matthews. 2001 “"They don’t like girls hanging around there': conflicts over recreational space in rural Northamptonshire.” Area 33(2): 161-168. doi:10.1111/14754762.00019 .

Valentine, G. 1996a. "Children should be seen and not heard: the production and transgression of adults' public space.” Urban Geography 17(3): 205-210. doi:10.2747/02723638.17.3.205.

Valentine, G. 1996b. “Angels and devils: moral landscapes of childhood.” Environment and Planning D: Society and Space 14(5): 581-599. doi:10.1068/d140581.

Valentine, G., M. Jayne and M. Gould. 2012. "Do as I say, not as I do: The affective space of family life and the generational transmission of drinking cultures." Environment and Planning A 44(4): 776-792. doi:10.1068/a4446.

Valentine, G., T. Skelton and D. Chambers 1998. "An introduction to youth and youth cultures" in Cool Places: Geographies of Youth Cultures. Edited by T. Skelton and G. Valentine, 1-33. London: Routledge.

Vanderbeck, R. 2007. “Intergenerational geographies: age relations, segregation and reengagements." Geography Compass 1(2): 200-221. doi:10.1111/j.1749-8198.2007.00012.x.

Wilkinson, S. 2015. "Young people, alcohol and urban life." Geography Compass. 9(3): 115126

Wimbush, E and M. Talbot. 1988. Relative Freedoms: Women and Leisure. Milton Keynes: Open University Press. 
Zeller, R.A. 1993. Focus Group Research on Sensitive Topics: Setting the Agenda without Setting the Agenda. London: Sage. 